AperTO - Archivio Istituzionale Open Access dell'Università di Torino

\title{
Autonomous hypercortisolism: definition and clinical implications
}

\section{This is the author's manuscript}

Original Citation:

Availability:

This version is available http://hdl.handle.net/2318/1700577

since 2019-05-02T13:29:11Z

Published version:

DOI:10.23736/S0391-1977.18.02884-5

Terms of use:

Open Access

Anyone can freely access the full text of works made available as "Open Access". Works made available under a Creative Commons license can be used according to the terms and conditions of said license. Use of all other works requires consent of the right holder (author or publisher) if not exempted from copyright protection by the applicable law. 


\section{Autonomous hypercortisolism: definition and clinical implications}

Journal: Minerva Endocrinologica

Paper code: Minerva Endocrinol-2884

Submission date: June 22, 2018

Article type: Review Article

Files:

1. Manuscript

Version: 2

Description: Manoscritto originale

File format: application/vnd.openxmlformats-officedocument.wordprocessingml.document

2. Figures 1

Version: 2

Description: Figura 1

File format: image/jpeg 


\section{Autonomous hypercortisolism: definition and clinical implications}

Giuseppe REIMONDO ${ }^{1}$, Soraya PUGLISI ${ }^{1}$, Anna PIA ${ }^{1}$, Massimo TERZOLO ${ }^{1}$.

Internal Medicine and Endocrinology Unit, Department of Clinical and Biological Sciences, University of Turin, AOU San Luigi Gonzaga, Orbassano, Italy

Correspondig Author:

Giuseppe Reimondo

Internal Medicine and Endocrinology Unit, Department of Clinical and Biological Sciences, University of Turin, AOU San Luigi Gonzaga, Regione Gonzole 10, 10043 Orbassano, Italy 
 \\ ABSTRACT}

In current practice, an adrenal adenoma usually comes as an unexpected byproduct of an imaging study performed for unrelated reasons, without any prior suspect of adrenal disease. Therefore, these tumors currently represent a public health challenge because they are increasingly recognized due to the widespread use of high-resolution cross-sectional imaging for diagnostic purposes. In radiology series, the prevalence of adrenal adenomas increases steeply with age, from around $3 \%$ below the age of 50 years up to $10 \%$ in the ageing population. These tumors may have clinical relevance because they are able to secrete cortisol autonomously, independently from the pituitary control, in up to $20 \%$ - $30 \%$ of patients. In most of the cases the resulting cortisol excess is insufficient to produce a typical Cushing phenotype but may have clinical consequences, such as hypertension, diabetes, obesity, dyslipidemia and osteoporosis.

Despite some controversy on the most effective diagnostic algorithm to geffine this subtle hypercortisolism, there is mounting evidence that a simple approach by using the 1-mg overnight dexamethasone suppression test (DST) may stratify patients for theireardiovascular risk. Crosssectional, retrospective studies showed that patients withincreasing/0igher cortisol following DST have an adverse cardiovascular risk profile and are at increased is $\mathrm{k}$ of death. Therefore, also a subtle autonomous cortisol excess is associated with increased morbidity and mortality, mainly of cardiovascular origin.

\section{KEY WORDS}

Adrenal adenoma

Hypercortisolism

Cushing's syndrome 


\section{INTRODUCTION}

Adrenal adenomas are benign tumors with a limited potential of malignant transformation. In current practice, an adrenal adenoma usually comes as an unexpected byproduct of an imaging study performed for unrelated reasons, without any prior suspect of adrenal disease. Therefore, they currently represent a public health challenge because they are increasingly recognized due to the widespread use of high-resolution cross-sectional imaging for diagnostic purposes.

These tumors may have clinical relevance because they are able to secrete cortisolautonomously, independently from the pituitary control, in up to $20 \%-30 \%$ of patients ${ }^{1}$. In most of the cases the resulting ACTH-independent cortisol excess is mild and insufficient to produce a typical Cushing phenotype (facial plethora, easy bruising, proximal muscle weakness, purple striae or weight gain with decreasing growth velocity). Considering the lack of classical external features of Cushing's syndrome (CS), this condition has been defined as subclinical Cushing's syndropge (SCS) ${ }^{2}$ (Table I). When adrenal adenomas are associated with highly predictive features of $\mathrm{CS}^{3}$, the ACTHindependent cortisol excess is usually promptly recognized. However, endogenous hypercortisolism is a rare disease with an estimated incidence of around 2.4 per million and a prevalence of 39.1 per million $^{4}$ and ACTH-independent cortisol excess due to adrenal adenoma represents only $10 \%$ of the overall causes. On the contrary, the epideniologic relevance of SCS due to adrenal incidentalomas is potentially high, considering that in radiology series theprevalence of adrenal adenomas is around $3 \%$ below the age of 50 years, with progressive inerease in older patients (up to $10 \%$ in the ageing population $)^{1}$ and in approximately $20-25 \%$ of them an autonomous cortisol secretion is reported. However, the demonstration of autonomous cortisol secretion could be extremely difficult in practice. The heterogeneity of clinical phenotye and a limited clinical experience make precocious diagnosis a major challenge and frequently SCS remain unrecognized for long time, due its subtle course. In the meanwhile, patients exposed to chronic albeit slight cortisol excess may have significant clinical consequence, such as hypertension, diabetes, obesity, dyslipidemia and osteoporosis.

\section{DEFINITION OF AUTONOMOUS ACTH-INDEPENDENT HYPERCORTISOLISM}

According to the Endocrine Society guidelines ${ }^{3}$, overt endogenous hypercortisolism should be investigated when clinical features and history are highly predictive. The recommended screening evaluation includes the following test: $1 \mathrm{mg}$ overnight dexamethasone suppression test, urinary free cortisol (UFC) and late night salivary cortisol. When at least two of them are positive, the diagnosis is confirmed. If an adrenal adenoma is detected by radiological imaging, the diagnosis of ACTHindependent CS requires low ACTH levels ( $<1.1$ pmol/L). This two-step diagnostic procedure is highly effective in presence of high clinical pre-test probability. However, most of the patients may 
present a mild disease, that is harder to detect. Thus, several studies have been focused on such patients with diabetes mellitus, osteoporosis, hypertension or obesity to screen for mild hypercortisolism. Although a widespread screening is not recommended, interestingly most of the detected cases with confirmed hypercortisolism had an adrenal dependent $\mathrm{CS}^{5-7}$. According to the ESE guidelines ${ }^{1}$, the best method to discover autonomous cortisol secretion is the 1 mg overnight dexamethasone suppression test $(1 \mathrm{mg}$-DST). Nevertheless, false positive or false negative results are reported, mainly due to variable absorption and metabolism of dexamethasone ${ }^{3}$. Many drugs cause false positive results, as phenytoin, increasing hepatic metabolism of dexamethasone mediated by CYP3A4 (phenobarbitone, carbamazepine or rifampicin) or raising CBG levels (oral estroprogestinic preparations). On the contrary, false negative results could be due to liver or renal failure, which reduce dexamethasone clearance.

Twenty-four hour UFC is widely used in the clinical practice, but considering that it reflects the measure of cortisol circulating levels after CBG saturation, it is less sensitive in patients with mild hypercortisolism or in patients with AI. Moreover, several limits have been seported due to the need of multiple collection, improper collection, high fluid intake or renainsufficiency ${ }^{8-10}$.

Although the LC-MS / MS technique is notavailable in all centers, it appears promising to improve diagnostic accuracy, since interference with other steroids is excluded. Therefore, it is the recommended technique for the eyaluation of UFC as first-line screening of $\mathrm{CS}^{3}$ and recent studies have confirmed higher sensitivity and specificity of J F w with LC-MS / MS ${ }^{11,12}$.

The evaluation of the circadian rhythm of corthol is one of the most important diagnostic clue since the loss of the ultradian pulsatility of cortisol secretion with high nocturnal values is pathognomonic of cortisol excess. However, methodiogical limits, in addition to the non-uniformity of pathological thresholds, makes the consent aifficult and the use not widespread, especially for mild hypercortisolism.

Newell-Price and colleagues ${ }^{13}$ first suggested the use of midnight serum cortisol as a screening test, and in recent years its higher sensitivity and specificity was reported ${ }^{14,15}$. Moreover, the midnight serum cortisol threshold of $148 \mathrm{nmol} / \mathrm{L}$ has been also documented to be related with an adverse cardiovascular $(\mathrm{CV})$ risk profile in patients with $\mathrm{AI}^{16}$. However, it requires hospitalization and cannot be proposed for routine clinical practice.

The introduction of midnight salivary cortisol has avoided hospitalization and has become one of the most important diagnostic tools in CS. A meta-analysis demonstrated an overall sensitivity of $92 \%$ and a specificity of $96 \%$, although there is no agreement on the definition of the cut-off and it is necessary to define the levels of normality in each laboratory ${ }^{17}, 18$. Only few studies have verified the diagnostic accuracy of salivary cortisol at midnight in subclinical hypercortisolism with results that 
are mostly lower than other tests. Recently, data published by Ceccato and colleagues ${ }^{19}$ have confirmed the reduced accuracy of midnight salivary cortisol in the screening of subclinical hypercortisolism, although measured by LC-MS/MS. Furthermore, it has not been shown to be a strong predictor of accelerated atherosclerosis in patients with subclinical hypercortisolism ${ }^{20}$.

Although low ACTH concentrations may support diagnosis of cortisol autonomous hypersecretion, in some cases non-suppressed ACTH levels are associated with pathological value of 1 mg-DST. A possible explanation can be due to analytical errors or interference in ACTH immunoassay. Particularly, negative impact of antibody interference in ACTH measurements was pecently reported in adrenal adenomas incidentally detected ${ }^{21}$. As no single routine tes is available to identify immunoassay interference, the same authors suggest to ensure collaboration between clinical and laboratory staff to avoid clinical misjudgments.

The usefulness of DHEAS measurements in the screening of subclinical hypercortisolism is still debated. In the last years DHEAS measurement had a renaissance in this setting also by using LCMS/MS. Lower DHEAS levels have been confirmed to be correlated to fingher cortisol secretion and in some cases with a worsen metabolic profile, Howerer, when compared with the $1 \mathrm{mg}$ DST the sensitivity and specificity in the detection of subclinical hypereortisolism ranges between $70-75 \%$ 22,23. More recently data on 185 patients with AI, of which 29 with subclinical hypercortisolism, DHEAS measurements calculated as age- and sex-specifice DHEAS ratios for all patients (derived by dividing the DHEAS by the lowerlimit of the respective reference range) seem to demonstrate that a single basal measurement of DHEAS offers comparable sensitivity and greater specificity to the existing gold-standard 1 mg DST for the detection of SCS in patients with $\mathrm{AI}^{24}$.

In conclusion, despite some controversies, use of the 1-mg DST as screening test meets the recent spending-review policies of healtheare systems and limit false positive results. Moreover, there is mounting evidence that the 1-mg DST is useful to stratify patients for their CV and metabolic risk.

Indeed, it has been demonstrated that patients with impaired suppression of cortisol after $1 \mathrm{mg}$ dexamethasone test have a higher risk of type 2 diabetes mellitus (T2D), hypertension, CV events and vertebral fractures.

Urine steroid metabolomics analysis should be a prospective and promising technique to differentiate secreting and non secreting adrenal tumors.

\section{MORBIDITY AND MORTALITY IN ADRENAL-DEPENDENT CUSHING'S SYNDROME} (ACS) 
The effects of hypercortisolism on morbidity and mortality have been extensively studied, but most published papers have focused on patients with Cushing's disease (CD) and fewer on patients with ACS. It is evident that the therapeutic approach to patients with $\mathrm{CD}$ is more complex and often requires different and sequential treatments with a persistent risk of hypercortisolism which is maintained for longer periods. As for patients with ACS, the therapeutic approach is by definition surgical and, in absence of clinical contraindications that determine a high operative risk, it results definitive obtaining the cure in $100 \%$ of the cases, although the negative effects of pre-surgical hypercortisolism cannot be removed. In this clinical context, however, post-surgical hypoadrenalism, often prolonged, must be considered until it becomes definitive and potentilinginfluences the quality of life and the clinical management of patients who are on steroid replacement therapy.

\section{METABOLIC AND CARDIOVASCULAR MORBIDITY}

Impaired glucose tolerance, hypertension, CV disease and thromboengodism are very common features of CS and frequently reported as risk faetors of mortality 25

It is known that patients with CS showed abdominal obesity (37-71\%) and dyslipidemia (hypercholesterolemia in 16-60\% and hypertriglyceridemiân $7-36 \%$ ) $^{26}$. This pattern is due to differential effects of GCs on visceral and peripheral adipose tissues. Indeed, the GC excess induces lipogenesis in visceral fat, whereas in peripheral fat it promotes lipolysis ${ }^{27}$. Moreover, hypercortisolism induces abnormalities in gluçse homeostasis, mainly caused by insulin resistance and impairment in insulin secretion, which may persist even after correction of glucocorticoid excess 28 .

In addition to inetabolic changes, patients with CS are frequently affected by hypertension (55-85\%), coagulopathy, struetural cardiac alterations (in $70 \%$ of cases abnormal left ventricular (LV) mass, with concentric hypertrophy or concentric remodelling) and endothelial dysfunction ${ }^{26}$.

Recently, new mechanisms are reported to explain the high CV risk in CS patients.

In 2015, Boero and colleagues carried out an open cross-sectional study to identify the presence of atherogenic risk factors in 32 patients with active CS compared with sex- and age-matched controls. Patients with CS showed lower insulin sensitivity, higher waist circumference, high oxidized lowdensity lipoprotein levels, high sensitive C-reactive protein levels and increased leukocyte count ${ }^{29}$. Moreover, in 2017, Gokosmanog and colleagues analyzed prevalence of obstructive sleep apnea (OSA) in 30 female patients with active CS and 30 matched healthy controls. They reported higher prevalence of OSA in patients with CS compared with control subjects with similar ages and BMI levels, identifying hypercortisolemia as an independent risk factor for OSA ${ }^{30}$. 
This multifactorial and variegated pathogenesis of CV morbidity in CS is summarized in Fig 1. However, data focused on adrenal-dependent CS are few and mostly collected aiming to evaluate the efficacy of treatment. At diagnosis, the prevalence of CV risk factors in patients with ACS seems to be similar to $\mathrm{CD}^{31}$, and higher than in BMI-matched controls ${ }^{32}$.

On the other hand, controversial data are available on the effect of therapy in reducing CV risk factors. When studies are predominantly focused on patients with $\mathrm{CD}$, disease remission appears to have only a moderately positive effect over the long term, while maintaining a higher risk compared to the general population ${ }^{33-34}$.

Although the risk of $\mathrm{CV}$ events is not completely eliminated, studies that inciude patients in remission with ACS demonstrate more successful results. Giordano and colleagues showed that a significant reduction in impaired glucose tolerance was achieved only in patients with ACS after only one year follow-up ${ }^{32}$. A recent study by Terzolo and colleagues has demonstrated, over a long period of follow-up a complete normalization of $\mathrm{CV}$ risk factors in a higher percentage of patients compared to previous publications, having included patients who had already completed the steroid replacement therapy, which had an average duration of aboyt 12 months. In other studies, some patients in remission had ongoing replacement therapy and the possible effect on CV risk outcomes should not be excluded, although further data are needed ${ }^{35}$

\section{OSTEOPOROSIS AND FRACTURERISK}

Osteoporosis is widely documented and up to $80 \%$ of patients with CS are reported with an associated risk of fractures exceeding $50 \%$. Moreover, unexpected osteroporosis for patient's age or the rapid worsening of bone minerandensity, represent relevant signs of CS. Osteoporosis and fracture risk has been well studiea io the different etiologies of Cushing following the hypothesis that the suppression of androgens in patients with ACS could determine a reduction of their protective effect on bone mass favoring the negative effect of excess cortisol. Some works have confirmed this hypothesis, demonstrating a correlation between DHEAS levels and bone mineral density ${ }^{36,37}$, while others did not highlight differences between etiologies ${ }^{38,39}$. It is likely that the controversial data depend on the different selection of patients, in particular regarding the gonadal status and the hormonal replacement therapy in patients with post-surgical pituitary deficiency.

\section{OTHER MORBIDITIES}

GC excess is associated with neuropsychiatric diseases, probably due to structural and functional changes in brain areas expressing GC receptors, such as the hippocampus, amygdala, and anterior cingulated cortex (limbic system, involved in emotional and cognitive attitudes). Particularly, in 
patients with CS is reported an high prevalence of major depression (50-81\%), anxiety (66\%), and bipolar disorders $(30 \%)^{40}$. It is worth of note that cognitive, psychiatric and mood disorders may persist also after resolution of cortisol excess, with a significant impact on quality of life ${ }^{41}$. Moreover, hypercortisolism impairs the immune system, causing immunosuppression and, consequently, susceptibility to infections (especially due to opportunistic pathogens). Interestingly, the increase risk of invasive infections appears to be independent of the etiology of CS, but is correlated with the severity of GC excess and the success in treatment of opportunistic infections frequently depends on the rapidity in normalizing cortisol levels ${ }^{25}$.

\section{MORTALITY}

Several data have been published in the last decade on mortality in patients with endogenous hypercortisolism confirming the expected excess compared to the general population, mainly due to cardio- and cerebro-vascular events or sepsis. The excessive mortality is described in patients with persistent disease, while patients in remission may haye a comparable risk to the general population or at least only a slight increase ${ }^{25}$.

The investigation of the Standard mortality ratio only in patients with adrenal-dependent benign unilateral adrenal adenoma vary greatly from 1.35 to 7.5 42-45 However, recent data from two large series with a prolonged follow-up reported that patients in remission with ACS does not have an excess risk mortality compared to the general population and it is similar or slightly lower than patients with $\mathrm{CD}^{45,46}$.

\section{MORBIDITY AND MORTALITY IN SUBCLINICAL CUSHING SYNDROME (SCS)}

An increasing body of evidence suggests association between SCS and metabolic alterations, CV disease and osteoporosis. Long-term exposure to even low-grade cortisol excess may have detrimental effects depending on individual genetic background, associated clinical conditions and degree of hypercortisolism. Moreover, recent studies showed higher mortality in this group of subjects.

\section{METABOLIC AND CARDIOVASCULAR MORBIDITY}

It is known the effect of glucocorticoids on glucose metabolism, including increase of hepatic gluconeogenesis, decrease of insulin-dependent glucose uptake in peripheral tissues and inhibition of insulin secretion from pancreatic $\beta$-cells ${ }^{47}$. Therefore, it is not surprising the association between SCS 
and impairment of glucose metabolism, including insulin resistance, impaired glucose tolerance (IGT) and T2M. High prevalence of IGT (36\%) or previously undiagnosed T2M (5\%) has been described since $2002^{48}$ in patients with AI in comparison with controls. Moreover, the same authors reported higher levels of 2-h glucose after oral glucose tolerance test (OGTT) $(\mathrm{p}=0.03)$ and reduced insulin sensitivity index (ISI) ( $\mathrm{p}<0.0001)$ in the subgroup of patients with adrenal adenoma and SCS compared to subgroup of patients with nonfunctioning adenoma. In the following years, several studies have been conducted in this field and it has been reported T2D roughly in one third of patients with SCS, but with a broad range from $5 \%$ to $69 \%$. This variability could depend on different diagnostic criteria used to define SCS, number of examined patients and different method used to evaluate the presence of glucose metabolism impairment. Particularly, it is yorth of note that assessment of fasting glucose and fasting insulin in SCS is not sufficient to detect glucose metabolism impairment and an OGTT is required ${ }^{50}$. Due to similar reasons (variability of diagnostic cut-off for SCS), the reported prevalence of mild hypercortisolism in cohorts of patienfs with T2D is extremely variable. In 2003 Catargi and colleagues described a $3.5 \%$ prevalence of $\$ C S$ in a population of 200 diabetic patients ${ }^{51}$, while in 2005 Chiodini and collegaues 52 reported@rough prevalence of 7\%, 4.8fold higher than in non-diabetic group, independenty of potentiany confounding comorbidities as obesity and hypertension. More recently, a large single center study, conducted in a cohort of 993 Asian Indian patients with T2D ${ }^{53}$, reported in 37 cases (3) $32 \%$ ) a value of cortisol after 1-mg DST > $50 \mathrm{nmol} / \mathrm{L}$. These patients have been further evaluated with a $48 \mathrm{~h}, 2 \mathrm{mg}$ low dose DST (LDDST) after a gap of at least 1 week after 1-mg DST and hone of them had cortisol >50 nmol/L, nor did they develop clinically eyident CS over a follow-up period of 1 year. Only on the basis of these biochemical and ciniseal data, the Authors concluded that none of the T2DM patients in their cohort had SCS. Conversely, Costa and colieagues ${ }^{54}$ reported, in a large sample of T2D patients with high $\mathrm{CV}$ risk, a prevalence of $8.6 \%$ of SCS. Moreover, these patients had more severe hypertension and increased aoitic stiffness, despite of a shorter diabetes duration. Regardless this variability of findings, currently it is suggested against systematic biochemical screening for SCS in T2D cohort, while diagnostic investigations should be reserved for cases of clinical suspicion. On the contrary, SCS patients had to be screened for T2D ${ }^{1}$. Although less proven, association with dyslipidemia is also plausible. Interestingly, Masserini and colleagues showed that in absence of impaired glucose metabolism a mild hypercortisolism has no effect on lipid pattern ${ }^{55}$. Finally, recent studies showed that patients with SCS have a high prevalence of nonalcoholic fatty liver disease ${ }^{56}$ and visceral fat accumulation (measured by CT-scan) ${ }^{57}$.

An increased CV risk profile in SCS subjects was first demonstrated in 2002, with a cross-sectional study including 28 SCS patients compared with 100 controls. Systolic and diastolic blood pressures, 
fasting glucose, insulin, total cholesterol, triglycerides, fibrinogen were higher in SCS patients, as were insulin resistance index, waist to hip ratio, mean carotid artery intima-media thickness and prevalence of atherosclerotic plaques. Moreover, among SCS patients it was reported a symptomatic $\mathrm{CV}$ disease in six subjects (21.3\%) and CV abnormalities (revealed by ultrasound scanning of carotid arteries and/or electrocardiogram records) in 11 cases $(39.3 \%)^{58}$. In 2005 a multicenter retrospective study including 210 patients with clinically inapparent adrenal adenoma reported higher fasting glucose and systolic blood pressure in patients with elevated midnight serum cortisol concentrations compared to subjects with normal cortisol levels ${ }^{16}$. A significance contribute was also provided by a cross-sectional study published in 2012, including 348 patients with AI, classified in 4 subgroups: 203 patients with non-secreting adenoma (NSA, with $1 \mathrm{mg}$ DST $<50$ mol/1), 19 patients with SCS ( $1 \mathrm{mg}$ DST $>138 \mathrm{nmol} / \mathrm{l}$ ) and the remaining patients with intermediate phenotype (1 mg DST between 50 and $138 \mathrm{nmol} / \mathrm{l}$ ), divided in minor (71 patients) or major (55 patients) according plasma ACTH and/or UFC levels. It is worth of note the increase of prevalence of myocarcialinfarction according to secreting pattern (2.9\% in NSA, $11.9 \%$ in patients withintermediate phenosype and $26.3 \%$ in SCS). Moreover, multivariate logistic regression analysis showed assoctation between prevalence of coronary heart disease and patients with intermediate phenotype or SCS, independently of other potential risk factors ${ }^{59}$. These important findings were confirmed by the same authors in a retrospective analysis of 198 patients, evaluated for theiroortisol secreting pattern at baseline and at the last visit, with a mean follow-up of $7.5 \pm 3.2$ years (range 26 months - 15 years). It was reported that patients with SCS and with worsening coffisel secretion at the last visit (compared to baseline) had higher incidence of $\mathrm{C} V$ disease than those with NSA. Moreover, increase of cortisol levels during follow-up was independently associated with higher rate of CV events ${ }^{60}$. Finally, the role of cortisol as a contributing factor to $\mathrm{CV}$ diseases was confirmed in other retrospective studies, reporting higher incidence of CV events in patients with SCS than in patients with NSA ${ }^{61-63}$.

More recently Arruda and colleagues, reported the association between hypertension and cortisol levels after $1 \mathrm{mg}$-DST in patients with $\mathrm{NSA}^{64}$. Although there is no indication to a routine screening for cortisol secretion in patients with hypertension, the high prevalence of SCS shown in patients with resistant hypertension, associated with several markers of worse CV prognosis ${ }^{65}$ probably needs further assessments.

\section{OSTEOPOROSIS AND FRACTURE RISK}

In the last decade, several studies investigated the impact of mild hypercortisolism on bone healthy. Retrospective series ${ }^{66-69}$ reported increased prevalence of bone fractures, mainly in trabecular bone, in patients with SCS compared to patients with NSA or healthy subjects. 
In 2011 a first longitudinal study confirmed higher prevalence of vertebral fractures and also reported, using the surrogate tool of spinal deformity index (SDI), worsened bone quality in SCS patients in comparison to patients with AI. Moreover, it was showed that SCS patients had higher risk to develop new vertebral fractures over time despite a stable bone mineral density (BMD) ${ }^{70}$.

Deterioration of bone quality in SCS patients was confirmed in a subsequent prospective study, in which trabecular bone score (TBS) was used as surrogate index of damaged bone microarchitecture. It was found that TBS was inversely correlated with 1-mg DST regardless of age, BMD, body mass index (BMI) and gender. Moreover, in patients with SCS, the presence of fractures was associated with low TBS, and its value predicted occurrence of new microfractures, tegardless of $\mathrm{BMD}^{71}$. Correlation between mild hypercortisolism and bone quality was further investigated in OsteoLaus cohort, including 608 women > 50 years old, in which salivary cortisol circadian rhythm was assessed. Lower TBS values $(\mathrm{p}=0.02)$, more vertebral fractures $(\mathrm{p}=0.012)$ and major osteoporotic fractures $(\mathrm{p}=0.042)$ were reported in women with $8 \mathrm{PM}$ salivary cortisol in the highesit tertile compared to women with salivary cortisol in lowest tertile, without difference in lumbar spine BMD ${ }^{72}$. In a recent study including 110 patients with overt Cushing (OC: UFC) $>1.5$ ULN and $1 \mathrm{mg}$ DST > $50 \mathrm{nmol} / \mathrm{L}$ ) or mild autonomous cortisol secretion (MACE: norma? UFC associated with $1 \mathrm{mg}$ DST $>50 \mathrm{nmol} / \mathrm{L}$ ), a group of 29 patients with MACE due to A was compared with a group 18 patients with NSA (normal UFC associated with $1 \mathrm{mg}$ DST < 50 nmol/L). Patients with MACE had lower TBS than patients with NSA ( $p<0.04)$, despite singiar BMD, age, BMI and female predominance. Moreover, $52 \%$ of patients with MACE and 33\% of patients with NSA $(p=0.05)$ had impaired bone microarchitecture (as indicated by their TBS) ${ }^{73}$.

\section{MORTALITY}

Recent studies have also shown that SCS is associated with an increase in mortality rate. A 15-year retrospective study ${ }^{60}$ showed that in 198 patients followed up for a mean 7.5 years 21 patients died, $48 \%$ attributable to CV disease and $43 \%$ due to cancer. All-cause (57 vs. $91 \%$ ) and CV specific mortality (78 vs. 98\%) survival rate was worse in SCS patients compared with NSA. Another retrospective, longitudinal cohort study ${ }^{62}$ involving 206 patients (mean follow-up 4.2 \pm 2.3 years), confirmed the relationship between a low-grade excess cortisol and an increased mortality rate. It is worth of note that patients with SCS showed higher mortality rate related to cardiovascular disease and infection when compared with UK population.

\section{CONCLUSION}

Since the first years of the new millennium, the growing number of incidentally discovered adrenal 
masses increased the interest on their clinical management, primarily in identifying malignancy, but also in demonstrating a potential increase in cortisol secretion and its consequences in patients who did not show any of the typical signs and symptoms of hypercortisolism. While in overt Cushing's syndrome it is clearly demonstrated that associated co-morbidities (CV events, metabolic syndrome, osteoporosis, psychiatric disorders, and infective diseases) contribute to an increase mortality risk, which is not always completely reversible after disease remission, in patients referred to the clinician for incidentally discovered adrenal masses, without any signs and symptoms of hypercortisolism, the diagnostic evaluation and the potential clinical implications were more complex to study and there are still unresolved questions. Although the measure of cortisol after overnignt $1 \mathrm{mg}$ DST is currently the most accurate, less expensive and easiest test to identify patients with an autonomous cortisol secretion, there are still areas of uncertainty in patients with cortisol levels higher than $50 \mathrm{nmol} / \mathrm{L}$. The addition of further hormone evaluations does not provide sufficient specificity, thus it is still crucial to identify new diagnostic methods, which allow to better measure tie chronic exposure to a slight cortisol excess. The assessment of potential co-ingrbidities is essential in identifying the best therapeutic approach. Many studies confirm a correlation between a orogressive increase of impaired glucose metabolism, CV events and osteoporosis with higher cortisol secretion and early data seem to demonstrate an increasing effect on mortality Actually further extensive studies are needed to better discriminate the effect of hypercortisolism, especially in older patients who have an age related co-morbidity risk. The prospective aim will be to ace urately identify and to categorize, from the initial clinical and biochemical assessment, patienso who can benefit from specific treatments for hypercortisolism. 


\section{REFERENCES}

1. Fassnacht M, Arlt W, Bancos I, Dralle H, Newell-Price J, Sahdev A, et al. Management of adrenal incidentalomas: European Society of Endocrinology Clinical Practice Guideline in collaboration with the European Network for the Study of Adrenal Tumors. Eur J Endocrinol. 2016 Aug;175(2):G1-G34

2. Terzolo M, Pia A, Reimondo G. Subclinical Cushing's syndrome: definition and management. Clin Endocrinol (Oxf). 2012 Jan;76(1):12-8

3. Nieman LK, Biller BM, Findling JW, Newell-Price J, Savage MO, Stewart PM, et al. The diagnosis of Cushing's syndrome: an Endocrine Society Clinical Practice Guideline. J Clin Endocrinol Metab. 2008 May;93(5):1526-40

4. Etxabe J, Vazquez JA: Morbidity and mortality in Cushing's disease: an eppidemiological approach. Clin Endocrinol (Oxf) 1994; 40: 479-484

5. Terzolo M, Reimondo G, Chiodini I, Castellø R, Giordano R, Ciecareni E, et al. Screening of Cushing's syndrome in outpatients with type 2 diabetes: results of a prospective multicentric study in Italy. J Clin Endocrinol Metab 2012: 97: 3467-3475.

6. Chiodini I, Mascia ML, Muscarella S, Battista C, Minisola S, Arosio M, et al. Subclinical hypercortisolism among outpatients referred for osteoporosis. Ann Intern Med 2007; 147: $541-548$

7. Omura M, Saito J, Yamaguchi K, Kakua Y, Nishikawa T. Prospective study on the prevalence of secondary bypertension among hypertensive patients visiting a general outpatient clinic in Japan. Hypertens Res 2004; 27: 193-202

8. Debono M, Newell-Price Nive. Cushing's Syndrome: Where and How to Find It. Front Horm Res 2016;46:15-27

9. Elamin MB, Murad MH, Mullan R, Erickson R, Harris K, Nadeem S, et al. Accuracy of diagnostic tests for Cushing's syndrome: a systematic review and metaanalyses. J Clin Endocrinol Metab 2008: 93; 1553-1562

10. Petersenn S, Newell-Price J, Findling JW, Gu F, Maldonado M, Sen K, et al. High variability in baseline urinary free cortisol values in patients with Cushing's disease. Clin Endocrinol (Oxf) 2014; 80: 261-269

11. Ceccato F, Barbot M, Zilio M, Frigo AC, Albiger N, Camozzi V, et al. Screening Tests for Cushing's Syndrome: Urinary Free Cortisol Role Measured by LC-MS/MS. J Clin Endocrinol Metab. 2015 Oct;100(10):3856-61 
12. Ceccato F, Antonelli G, Frigo AC, Regazzo D, Plebani M, Boscaro M, et al. First-line screening tests for Cushing's syndrome in patients with adrenal incidentaloma: the role of urinary free cortisol measured by LC-MS/MS. J Endocrinol Invest. 2017 Jul;40(7):753-760

13. Newell-Price J, Trainer P, Perry L, Wass J, Grossman A, Besser M. A single sleeping midnight cortisol has $100 \%$ sensitivity for the diagnosis of Cushing's syndrome. Clin Endocrinol (Oxf). 1995 Nov;43(5):545-50

14. Papanicolaou DA, Yanovski JA, Cutler GB Jr, Chrousos GP, Nieman LK. A single midnight serum cortisol measurement distinguishes Cushing's syndrome from pseudoCushing states. J Clin Endocrinol Metab. 1998 Apr;83(4):1163-7

15. Reimondo G, Allasino B, Bovio S, Paccotti P, Angeli A, Terzolo M. Evaluation of the effectiveness of midnight serum cortisol in the diagnostic procedures for Cushing's syndrome. Eur J Endocrinol. 2005 Dec;153(6):803-9

16. Terzolo M, Bovio S, Pia A, Conton PA, Reimonde G, Dall'Asta C, ê a MMidnight serum cortisol as a marker of increased cardiovascular risk in patients with a clinically inapparent adrenal adenoma. Eur J Endocrinol. 2005 Aug; 153 (2):307-150)

17. Masserini B, Morelli V, Bergamaschi S, Ermetici F, Eller-Vainicher C, Barbieri AM, et al. The limited role of midnight saliyary cortisol levels in the diagnosis of subclinical hypercortisolism in patients with adrenal incidentaloma. Eur J Endocrinol. 2009 Jan;160(1):87-92

18. Nunes ML, Vattaut S, Corcuff JB, Raufes, Loiseau H, Gatta B, et al. Late-night salivary cortisol for diagnosis of oyert and subclinical Cushing's syndrome in hospitalized and ambulatory patients. I Clin Endocrinol Metab. 2009 Feb;94(2):456-62

19. Ceccato F, Barbot M, Albiger N, Antonelli G, Zilio M, Todeschini M, et al. Daily salivary cortisol and cortisone rhythm in patients with adrenal incidentaloma. Endocrine. 2018 Mar:59(3):510-519

20. Reimondo G, Allasino B, Coletta M, Pia A, Peraga G, Zaggia B, et al. Evaluation of Midnight Salivary Cortisol as a Predictor Factor for Common Carotid Arteries Intima Media Thickness in Patients with Clinically Inapparent Adrenal Adenomas. Int J Endocrinol. 2015; 674734

21. Yener S, Demir L, Demirpence M, Mahmut Baris M, Simsir IY, Ozisik S, et al. Interference in ACTH immunoassay negatively impacts the management of subclinical hypercortisolism. Endocrine. 2017 May;56(2):308-316 
22. Di Dalmazi G, Fanelli F, Mezzullo M, Casadio E, Rinaldi E, Garelli S, et al. Steroid Profiling by LC-MS/MS in Nonsecreting and Subclinical Cortisol-Secreting Adrenocortical Adenomas. J Clin Endocrinol Metab. 2015 Sep;100(9):3529-38

23. Yener S, Yilmaz H, Demir T, Secil M, Comlekci A. DHEAS for the prediction of subclinical Cushing's syndrome: perplexing or advantageous? Endocrine. 2015 Mar;48(2):669-76

24. Dennedy MC, Annamalai AK, Prankerd-Smith O, Freeman N, Vengopal K, Graggaber J, et al. Low DHEAS: A Sensitive and Specific Test for the Detection of Subcinical Hypercortisolism in Adrenal Incidentalomas. J Clin Endocrinol Metab. 2017 Mar $1 ; 102(3): 786-792$

25. Pivonello R, Isidori AM, De Martino MC, Newell-Price J, Biller BM, Colao A. Complications of Cushing's syndrome: state of the art. Lancet Diabetes Endocrinol. 2016Jul;4(7):611-29

26. Ferrau F, Korbonitz M. Metabolic comorbidities in Cushing's syndrome. Eur J Endocrinol. 2015 Oct; 173(4): M133-57

27. Scaroni C, Zilio M, Foti M, Boscaro M. Glucose metabolism abnormalities in Cushing syndrome: from molecular basis to clinical management. Endocr Rev. 2017 Jun; 38(3):189219

28. Mazziotti G, Formenti AM, Frara S, Maffezzoni E, Doga M, Giustina A. Diabetes in Cushing disease. Curr Diab Rep. 2017 May; 17(5):32

29. Boero L, Manavela M, BottaE, Malleargil MS, Katz D, Meroño T, Tetzlaff W, Martin M, Gómez Rosso J, Danitowicz K, Brites F. Conditioning factors for high cardiovascular risk in patients with Cushing syndrorne. Endocr Pract. 2015 Jul; 21(7): 734-42

30. Gokosmaneg Lu F, Güzê, A, Kan EK, Atmaca H. Increased prevalence of obstructive sleep apnea in patients with Cushing's syndrome compared with weight- and age-matched controls. Eur J Endocrinol. 2017 Mar; 176(3): 267-272

31. Valassi E, Santos A, Yaneva M, Tóth M, Strasburger CJ, Chanson P, et al.; ERCUSYN Study Group. The European Registry on Cushing's syndrome: 2-year experience. Baseline demographic and clinical characteristics. Eur J Endocrinol. 2011 Sep;165(3):383-92

32. Giordano R, Picu A, Marinazzo E, D'Angelo V, Berardelli R, Karamouzis I, et al. Metabolic and cardiovascular outcomes in patients with Cushing's syndrome of different aetiologies during active disease and 1 year after remission. Clin Endocrinol (Oxf). 2011 Sep;75(3):354-60 
33. Colao A, Pivonello R, Spiezia S, Faggiano A, Ferone D, Filippella M, et al. Persistence of increased cardiovascular risk in patients with Cushing's disease after five years of successful cure. J Clin Endocrinol Metab. 1999 Aug;84(8):2664-72

34. Faggiano A, Pivonello R, Spiezia S, De Martino MC, Filippella M, Di Somma C, et al. Cardiovascular risk factors and common carotid artery caliber and stiffness in patients with Cushing's disease during active disease and 1 year after disease remission. J Clin Endocrinol Metab. 2003 Jun;88(6):2527-33

35. Terzolo M, Allasino B, Pia A, Peraga G, Daffara F, Laino F, et al. Surgical rernission of Cushing's syndrome reduces cardiovascular risk. Eur J Endocrinol. 2014 Ju1:171(1):127-36

36. Kawamata A, Iihara M, Okamoto T, Obara T. Bone mineral density before and after surgical cure of Cushing's syndrome due to adrenocortical adenoma: prospective study. World J Surg. 2008 May;32(5):890-6

37. Minetto M, Reimondo G, Osella G, Ventura M, Angeli A, Terzolo M. Bone loss is more severe in primary adrenal than in pituitary-dependent Cushing's fyndosme. Osteoporos Int. 2004 Nov;15(11):855-61

38. Tauchmanovà L, Pivonello R, Di Somma C, Rossi R, Dé Martino MC, Camera L, et al. Bone demineralization and vertebral fractures in endegenous cortisol excess: role of disease etiology and gonadal status. J Clin Endocrinol Metab. 2006 May;91(5):1779-84

39. Barahona MJ, Sucunza N, Resmini E, Ferräidez-Real JM, Ricart W, Moreno-Navarrete JM, et al. Deleterious effects of glucocorticgid replacement on bone in women after long-term remission of Cushing's syndrome f Bone Miner Res. 2009 Nov;24(11):1841-6

40. Pivonello R, Simeoli C, De Diartino MC, Cozzolino A, De Leo M, Iacuaniello D, Pivonello C, Negri M, Pellecchia Mr. Iasevoli F, Colao A. neuropsychiatric disorders in Cushing's syndrome. Front Neurosci. 2015 Apr; 9:129

41. Webb SM, Valassi E. Morbidity of Cushing's syndrome and impact of treatment. Endocrinol Metab Clin North Am. 2018 Jun; 47(2):299-311.

42. Pikkarainen L, Sane T, Reunanen A. The survival and well-being of patients treated for Cushing's syndrome. J Intern Med 1999; 245: 463-68

43. Lindholm J, Juul S, Jørgensen JO, Astrup J, Bjerre P, Feldt-Rasmussen U, et al. Incidence and late prognosis of cushing's syndrome: a population-based study. J Clin Endocrinol Metab. 2001 Jan;86(1):117-23

44. Bolland MJ, Holdaway IM, Berkeley JE, Lim S, Dransfield WJ, Conaglen JV, et al. Mortality and morbidity in Cushing's syndrome in New Zealand. Clin Endocrinol (Oxf). 2011 Oct;75(4):436-42 
45. Yaneva M, Kalinov K, Zacharieva S. Mortality in Cushing's syndrome: data from 386 patients from a single tertiary referral center. Eur J Endocrinol 2013; 169: 621-27

46. Ntali G, Asimakopoulou A, Siamatras T, Komninos J, Vassiliadi D, Tzanela M, et al. Mortality in Cushing's syndrome: systematic analysis of a large series with prolonged follow-up. Eur J Endocrinol. 2013 Oct 8;169(5):715-23

47. Giordano R, Guaraldi F, Berardelli R, Karamouzis I, D'Angelo V, Marinazzo E, et al. Glucose metabolism in patients with subclinical Cushing's syndrome. Endocrine. 2012 Jun;41(3):415-23

48. Terzolo M, Pia A, Alì A, Osella G, Reimondo G, Bovio S, et al. Adrenal incidentaloma: a new cause of the metabolic syndrome? J Clin Endocrinol Metab.2002 Mar;87(3):998-1003

49. Di Dalmazi G, Pasquali R, Beuschlein F, Reincke M. Subclinical hypercortisolism: a state, a syndrome, or a disease? Eur J Endocrinol. 2015 Oct;173(4):M61-71

50. Otsuki M, Kitamura T, Tamada D, Tabuchi Y, Mukai K, Morita S, ef a Incompatibility between fasting and postprandial plasma glucose in patients withreushing's syndrome. Endocr J. 2016 Nov 30;63(11):1017-1023

51. Catargi B, Rigalleau V, Poussin A, Ronci-Cha1x N, Bex V. Vergnot V, et al. Occult Cushing's syndrome in type-2 diabetes. J Clin Endocrinol Metab. 2003 Dec;88(12):5808-13

52. Chiodini I, Torlontano M, Scillitan A, Arosio MD,Bacci S, Di Lembo S, et al. Association of subclinical hypercortisolism with type 2 diabetes mellitus: a case-control study in hospitalized patients. Eur J Endocrinol.2005 Dec;153(6):837-44

53. Budyal S, Jadhav SS, Kasaliwal R, Patt H, Khare S, Shivane V, et al. Is it worthwhile to screen patients with type 2 diabetes mellitus for subclinical Cushing's syndrome? Endocr Connect. 2015 Dec; $4(4): 242-8$

54. Costa DS, Conceição FL, Leite NC, Ferreira MT, Salles GF, Cardoso CR. Prevalence of subclinical hypercortisolism in type 2 diabetic patients from the Rio de Janeiro Type 2 Diabetes Cohort Study. J Diabetes Complications. 2016 Aug;30(6):1032-8

55. Masserini B, Morelli V, Palmieri S, Eller-Vainicher C, Zhukouskaya V, Cairoli E, et al. Lipid abnormalities in patients with adrenal incidentalomas: role of subclinical hypercortisolism and impaired glucose metabolism. J Endocrinol Invest. 2015 Jun;38(6):623-8

56. Papanastasiou L, Pappa T, Samara C, Apostolopoulou G, Tsiavos V, Markou A, et al. Nonalcoholic fatty liver disease in subjects with adrenal incidentaloma. Eur J Clin Invest. 2012 Nov;42(11):1165-72 
57. Debono M, Prema A, Hughes TJ, Bull M, Ross RJ, Newell-Price J. Visceral fat accumulation and postdexamethasone serum cortisol levels in patients with adrenal incidentaloma. J Clin Endocrinol Metab. 2013 Jun;98(6):2383-91

58. Tauchmanovà L, Rossi R, Biondi B, Pulcrano M, Nuzzo V, Palmieri EA, et al. Patients with subclinical Cushing's syndrome due to adrenal adenoma have increased cardiovascular risk. J Clin Endocrinol Metab. 2002 Nov;87(11):4872-8

59. Di Dalmazi G, Vicennati V, Rinaldi E, Morselli-Labate AM, Giampalma E, Mosconi C, et al. Progressively increased patterns of subclinical cortisol hypersecretion in adrenal incidentalomas differently predict major metabolic and cardiovascalar outcomes: a large cross-sectional study. Eur J Endocrinol. 2012 Apr;166(4):669, 77

60. Di Dalmazi G, Vicennati V, Garelli S, Casadio E, Rinaldi E, Giampalma E, et al. Cardiovascular events and mortality in patients with adrenal incidentalomas that are either non-secreting or associated with intermediate phenotype or subclinical Cushing's syndrome: a 15-year retrospective study. Lancet Diabetes Endocringl. 2014 Mlay 2(5):396-405

61. Morelli V, Reimondo G, Giordano R, Deilla Casa S, Policola C., Palmieri S, et al. Long-term follow-up in adrenal incidentalomas: an Italian multicenter study. J Clin Endocrinol Metab. 2014 Mar;99(3):827-34

62. Debono M, Bradburn M, Bull M, Harrison B, Ros. RJ, Newell-Price J. Cortisol as a marker for increased mortality in patients with incidental adrenocortical adenomas. J Clin Endocrinol Metab 2014 Dec:99(12):4468 70

63. Morelli V, Palmieris, Lania A, Trésoldi A, Corbetta S, Cairoli E, et al. Cardiovascular events in patients with mild antonomous cortisol secretion: analysis with artificial neural networks. Eur J Endocrinon $2017 \mathrm{Jul}$;177(1):73-83.

64. A.ruda M, Mello Ribeiro Cavalari E, Pessoa de Paula M, Fernandes Cordeiro de Morais F, Furtado Bilro G, Alves Coelho MC, et al. The presence of nonfunctioning adrenal incidentalomas increases arterial hypertension frequency and severity, and is associated with cortisol levels after dexamethasone suppression test. J Hum Hypertens. 2017 Dec;32(1):3-11

65. Martins LC, Conceição FL, Muxfeldt ES, Salles GF. Prevalence and associated factors of subclinical hypercortisolism in patients with resistant hypertension. J Hypertens. 2012 May;30(5):967-73

66. Chiodini I, Guglielmi G, Battista C, Carnevale V, Torlontano M, Cammisa M, et al. Spinal volumetric bone mineral density and vertebral fractures in female patients with adrenal incidentalomas: the effects of subclinical hypercortisolism and gonadal status. J Clin Endocrinol Metab. 2004 May;89(5):2237-41 
67. Tauchmanovà L, Pivonello R, De Martino MC, Rusciano A, De Leo M, Ruosi C, et al. Effects of sex steroids on bone in women with subclinical or overt endogenous hypercortisolism. Eur J Endocrinol. 2007 Sep;157(3):359-66

68. Chiodini I, Viti R, Coletti F, Guglielmi G, Battista C, Ermetici F, et al. Eugonadal male patients with adrenal incidentalomas and subclinical hypercortisolism have increased rate of vertebral fractures. Clin Endocrinol (Oxf). 2009 Feb;70(2):208-13

69. Chiodini I, Morelli V, Masserini B, Salcuni AS, Eller-Vainicher C, Viti R, et a1. Bone mineral density, prevalence of vertebral fractures, and bone quality in patients with adrenal incidentalomas with and without subclinical hypercortisolism: an Italian multicenter study. $\mathbf{J}$ Clin Endocrinol Metab. 2009 Sep;94(9):3207-14

70. Morelli V, Eller-Vainicher C, Salcuni AS, Coletti F, Iorio L, Muscogiuri G, et al. Risk of new vertebral fractures in patients with adrenal incidentaloma with and whout subclinical hypercortisolism: a multicenter longitudinal study. JBone Miner Res 201 Aug;26(8):1816-21

71. Eller-Vainicher C, Morelli V, Ulivieri FM, Palmieris, Zhuk@uskaya VV, Cairoli E, et al. Bone quality, as measured by trabecular bone score in patients with adrenal incidentalomas with and without subclinical hypercortiselism. J Bone Miner Res. 2012 Oct;27(10):2223-30

72. Gonzalez Rodriguez E, Lamy O, Stoll D, Metzger M, Preisig M, Kuehner C, et al. High Evening Cortisol Level is Asseciated With Z Fractures: OsteoLaus Study. I Clin Endoreninol Metab. 2017 Jul 1;102(7):2628-2636.

73. Vinolas H, Grouthier V, Mehsen-Cetre N, Boisson A, Winzenrieth R, Schaeverbeke T, et al. Assessment of vertebral micworenitecture in overt and mild Cushing's syndrome using trabecular oone seore. Clin Endocrinol (Oxf). 2018 May 2

Tab I. Relevant differences between Subclinical Cushing Syndrome and Overt Cushing Syndrome.

\begin{tabular}{|c|c|c|}
\hline & $\begin{array}{l}\text { SUBCLINICAL CUSHING } \\
\text { SYNDROME }\end{array}$ & $\begin{array}{l}\text { OVERT CUSHING } \\
\text { SYNDROME }\end{array}$ \\
\hline Age at diagnosis & Frequently $>50$ years & Frequently $<50$ years \\
\hline Sex & Slight prevalence in women & Clear prevalence in women \\
\hline $\begin{array}{l}\text { Presentation and } \\
\text { cause of disease }\end{array}$ & $\begin{array}{l}\text { Usually, adrenal mass incidentally finding } \\
\text { during radiological exams, in patients with } \\
\text { characteristics of metabolic syndrome, }\end{array}$ & Clinical suspect on the basis of \\
\hline
\end{tabular}


Page 20 of 21

\begin{tabular}{lll}
\hline & without specific features of Cushing & $\begin{array}{l}\text { specific signs of Cushing, followed by } \\
\text { radiological exams frequently showing } \\
\text { a pituitary adenoma }\end{array}$ \\
Disease course & $\begin{array}{l}\text { Usually does not progress to overt } \\
\text { Cushing's syndrome }\end{array}$ & Usually progressive to more severe \\
& clinical presentation \\
Prevalence of & Hypoadrenalism may results \\
hypoadrenalism & after removal of adrenal tumor & Hypoadrenalism invariably follow \\
after surgery & & removal of causing tumor \\
\hline
\end{tabular}

Modified from Terzolo at al. ${ }^{2}$ 
Page 21 of 21

1

2

3

4

5

6

7

8

9

10

11

12

13

14

15

16

17

18

19

20

21

22

23

24

25

26

27

28

29

30

31

32

33

34

35

36

37

38

39

40

41

42

43

44

45

46

47

48

49

50

51

52

53

54

55

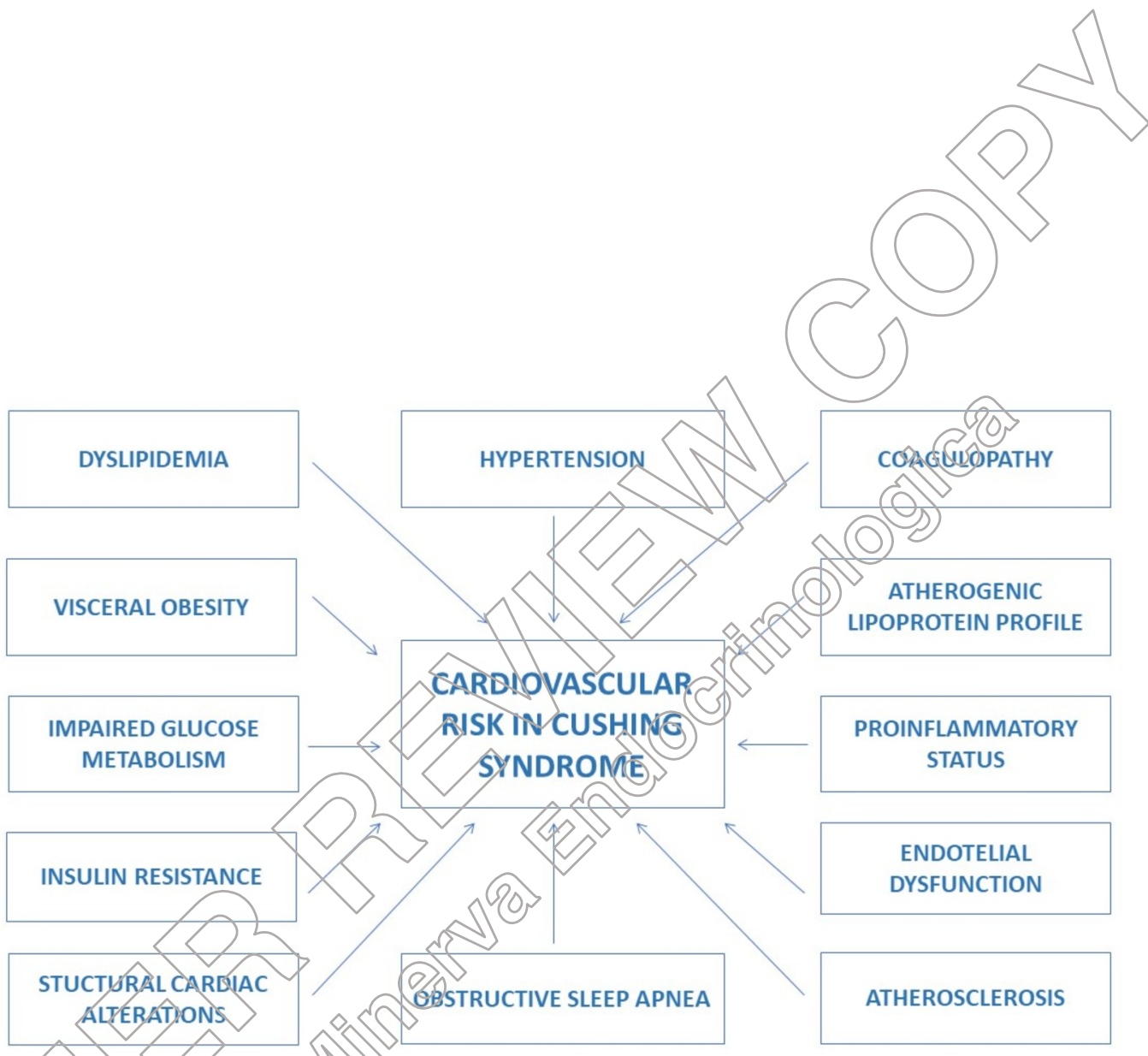

